\title{
Difficulties of treatment of patients with tuberculosis and medical recommendations performed by them
}

\author{
Sergey A. Yudin, A.S. Borzenko, V.V. Delaryu, A.A. Kaluzhenina \\ Volgograd State Medical University, Volgograd, Russia
}

Accepted 25 August 2014

Original Text (C) Yudin S.A., Borzenko A.S., Delaryu V.V., Kaluzhenina A.A., 2013, published in Saratov Journal of Medical Scientific Research 2013 ; 9(4): 741-743.

\begin{abstract}
Purpose - To study the reasons influencing the treatment of patients. Material and Methods - Anonymous questioning of patients with tuberculosis in number of 584 people being on treatment in antituberculosis hospitals, 92 phthisiopulmonologists and 144 therapists of Volgograd was performed. Results - The conducted research testifies that patients with tuberculosis consider that they observe medical recommendations completely in $76.5 \%$ of cases, and the opinion of medical workers was completely opposite, only $4.3 \%$ of phthisiopulmonologists and $2.8 \%$ of therapists. Most doctors were sure that medical recommendations were carried out by only a half of tuberculosis patients that was told by $54.4 \%$ of phthisiopulmonologists and $31.3 \%$ of therapists. Conclusion - Commitment formation to treatment at patients with tuberculosis should be carried out taking into account those difficulties and problems which are specified by patients, and also critical evaluation of performance by patients of the medical recommendations influencing the result of treatment. At the solution of medical problems phthisiopulmonologists did not pay enough attention to influence of psychological factors, taking into account available gender, age and educational level of the patient that compels to look for new ways of interaction of phthisiopulmonologists and psychotherapists in development of the individual plan of treatment and rehabilitation of every patient with tuberculosis.
\end{abstract}

Keywords: tuberculosis, commitment to treatment of patients, questioning, medical recommendations

Cite as Yudin SA, Borzenko AS, Delaryu VV, Kaluzhenina AA. Difficulties of treatment of patients with tuberculosis and medical recommendations performed by them. Russian Open Medical Journal 2014; 3: 0307.

Correspondence to Sergey A. Yudin. Phone: +79050618725. E-mail: su1694@yandex.ru

\section{Introduction}

Modern method of treatment of tuberculosis (TBC) patients is that a controlled course of chemotherapy is been carrying out during a long time. A hospital treatment stage is a significant and basic part of a therapy and administration [1]. Patients face various difficulties during the treatment process: medical, social and psychological problems reduce the efficiency of the treatment.

The therapy process goes on the background of an interaction between the doctor and a patient, but it depends most on a patient's treatment compliance [2].

The study aimed the reasons effecting on the patient's treatment compliance.

\section{Material and methods}

584 TBC patients of a stationary treatment underwent an anonymous survey in a tuberculosis dispensary (continuous nested sampling). Doctors also took the survey: 92 tuberculotherapists (the hard data method) and 144 therapists (continuous nested sampling). The survey was organized in Volgograd in 2012 according to sociology norms and standards [3]. The Student's ttest was used to evaluate the results validity.

\section{Results}

Medical recommendations are followed by the questioned patiens: $76.5 \%$ - "fully", 19.9\% - "partially" and 1.9\% - "practically do not follow". $1.7 \%$ of the patients did not know.

Women more often fully follow the recommendations $-82.0 \%$ than men $-74.7 \%(p<0.01), 81.7 \%$ of the patients had a higher education and $75.7 \%$ had a secondary education ( $p<0.02$ ). $21.4 \%$ of the male patients follow the instructions partially, $15.3 \%$ female patients $(p<0.01), 21.1 \%$ of them are with a secondary education, $12.2 \%$ had a higher education $(p<0.001)$.

The patients with a higher education practically did not follow the medical recommendations more often than with a secondary education, but there were very few of them $(3.7 \%$ and $1.6 \%$ of the cases respectively) $(p<0.05)$. There had not been revealed a significant influence on the given parameter of age and gender factors ( $p>0.05)$.

Men had more difficulties with an exact answer than women $2.1 \%$ and $0.7 \%$ respectively $(p<0.05)$.

Healthcare practitioners had another point of view about this question. Thus, $54.4 \%$ of tuberculotherapists assumed that about a half of the TBC patients followed the medical recommendations; $33.7 \%$ of specialists think that $20-30 \%$ of the patients follow the recommendations; $5.4 \%$ answered that only several patients 
comply with instructions, and only $4.3 \%$ of tuberculotherapists said that almost all of the patients followed practically all recommendations $(2.2 \%$ of the TBC patients were not sure about the exact answer).

If the work place (dispensary or inpatient department) did not effect the respondents' opinion, then the years of experience did: $58.0 \%$ of tuberculotherapists with more than a 10-year experience and $43.5 \%$ of their less experienced colleagues think that complaints are about a half of the patients $(p<0.05) ; 30.5 \%$ and $43.5 \%$ of tuberculotherapists ( $p>0.05$ ) (respectively) thought that only $20-30 \%$ of the patients follow the instructions. This means that more experienced specialists evaluated the compliants higher.

As for therapists, $31.3 \%$ of them answered that about half of the TBC patients follow the medical recommendations; almost the same number of doctors (33.3\%) said that it was typical to no more than $20-30 \%$ patients; $24.3 \%$ of the doctors included only a few patients with those who were compliants and $2.8 \%$ of the specialists of the general hospital assumed that almost all of the TBC patients followed the medical recommendations (this point of view was typical to therapists only, and with experience up to 10 years - at $7.9 \%$ of doctors versus $0.9 \%$ of their more experienced colleagues; $p<0.01$ ). The other $8.3 \%$ of the respondents were not sure about the answers.

Thus, the doctors' opinions about following the medical recommendations turned out to be similar, although therapists (comparing with tuberculotherapists) were skeptical of the patients' compliance.

According to survey results, the most of the difficulties in the tuberculosis therapy, as $35.3 \%$ of the patients say, are connected with medication side effects, $32.3 \%$ of them point out the necessity to stay in a tuberculosis dispensary for a long time, $22.6 \%$ - mark a negative reaction of people to TBC patients, $20.5 \%$ - the absence of needed medications, $19.5 \%$ - "presence of various diseases", $14.1 \%$ - no belief in cure, $6.5 \%$ - no support from family. $4.9 \%$ of the patients pointed other reasons, $7.5 \%$ could not answer. $16.4 \%$ of the patients had not any difficulties with the treatment.

Women pointed side effects of the medications more often than men $(49.3 \%$ and $30.4 \%$ respectively; $p<0.001)$, and patients with a higher education $(47.6 \%$ versus $33.3 \%$ among he patients with a secondary education; $p<0.001)$.

The younger patients were bored with the necessity to be in a tuberculosis dispensary more than elder persons $(34.1 \%$ and $25.3 \%$ respectively; $p<0.001)$ and the patients with a higher education $(41.5 \%$ versus $31.5 \%$ among the persons with a secondary education; $p<0.001$ ).

Young patients more often had a negative reaction of people on TBC persons ( $24.4 \%$ versus $11.4 \%$ at elder persons; $p<0.001$ ) and people with a higher education (30.5\% versus $21.3 \%$ among the patients with a secondary education; $p<0.01$ ).

Young patients pointed the absence of needed medications more often that patients over 60 years old $(21.8 \%$ and $12.6 \%$ respectively; $p<0.001$ )

It is clear that the patients over 60 years old noticed comorbid conditions ( $34.1 \%$ versus $25.3 \%$ of the tounger patients; $p<0.01$ ), women suffered it more than men $(24.7 \%$ and $17.7 \%$ respectively; $\mathrm{p}<0.05)$.

It is also evident that old patients more often had been said that they had no belief in cure than younger patients $(18.9 \%$ and $13.1 \%$ respectively; $\mathrm{p}<0.05)$, and the patients with a higher education (18.3\% versus $13.4 \%$ among the persons with a secondary education; $p>0.05)$.

Among the patients who denied any difficulties of the treatment there were 2 times more men than women $(19.1 \%$ and $8.7 \%$ respectively; $p<0.001$ ).

\section{Discussion}

The comparative analysis of the doctors' opinions (tuberculotherapists and therapists) and the TBC patients displayed that the doctors' and the patients' points of view about the medical recommendations are almost completely different. Only $4.3 \%$ of thetuberculotherapists and $2.8 \%$ of the therapists of the general hospital assume that practically all TBC patients follow the medical recommendations, while $96.4 \%$ of the patients say that they follow the instructions fully or partially.

Medical factors leading to a noncompliance may be explained by the features of chemotherapy. It should be noticed the group of psychological factors as negative reaction of people, no belief in cure, no family support. All these factors effect on a psychological background of the patients, and cause their negative reaction on the therapy and medical professionals.

So, the medication side effects influence negatively mostly the treatment of women with a higher education. The necessity of a prolonged standing in a tuberculosis dispensary cause the most difficulties in the old patients. Young patients with a higher education feel the bite of the negative attitude towards TBC patients. Patients younger than 60 years pay their attention to the absence of needed medications. A number of diseases caused difficulties in old female patients, and the absence of belief is typical to persons over 60 years old.

Male patients had minimum problems with tuberculosis treatment.

\section{Conclusion}

As can be seen from the above, the study shows that TBC patients are sure that they fully follow the medical recommendations in $76.5 \%$ of cases, but medical professionals have a completely opposite point of view - only $4.3 \%$ of tuberculotherapists and $2.8 \%$ of the therapists thought this. The most of the doctors are sure that a half of the patients followed the medical recommendations $-54.4 \%$ of tuberculotherapists and $31.3 \%$ of the therapists confirmed this.

Forming of compliance should be performed according to the difficulties and problems which are noted by the patients themselves, and a critical estimate of a compliance, which effect on the result of a treatment.

Tuberculotherapists pay little attention to managing psychological factors with account of gender, age and educational level of a patient. This makes find other methods of interaction between tuberculotherapists and psychotherapists in elaborating of an individual treatment and rehabilitation plan for every TBC patient.

Conflict of interest: none declared.

\section{References}

1. Shilova M V. Tuberculosis in Russia in 2009. Moscow, 2010; 192 p. Russian 
2. Bogorodskaya EM. Patients with tuberculosis: motivation for treatment. Tuberkulyoz i Bolezni Lyogkikh 2009; 86(2): 3-10. Russian

3. Devjatko IF. Social research methods. 6th edition. Moscow: KDU, 2010; 295 p. Russian

Authors:

Sergey A. Yudin - MD, PhD, Department of Phthisiopulmonology, Volgograd State Medical University, Volgograd, Russia;

A.S. Borzenko - MD, D.Sc., Professor, Head of Department of Phthisiopulmonology, Volgograd State Medical University, Volgograd, Russia;

V.V. Delaryu - MD, D.Sc., Professor, Department of General and Clinical Psychology, Volgograd State Medical University, Volgograd, Russia;

A.A. Kaluzhenina - MD, PhD, Assistant, Department of Phthisiopulmonology, Volgograd State Medical University, Volgograd, Russia. 